\title{
Regulation of Nutritional Metabolism in Different Perinatal Period of Does: Energy Metabolism Efficiency, Lipid Metabolism, Oxidative Stress and Liver Metabolomics Profile in Response to Nicotinamide Supplementation
}

\author{
Xiaoshi Wei \\ Zhejiang Agriculture and Forestry University: Zhejiang A and F University \\ Qingyan Yin \\ Northwest A\&F University: Northwest Agriculture and Forestry University \\ Huihui Zhao \\ Northwest A\&F University: Northwest Agriculture and Forestry University \\ Jiajun He \\ Northwest A\&F University: Northwest Agriculture and Forestry University \\ Yangchun Cao \\ Northwest Agriculture and Forestry University \\ Junhu Yao ( $\square$ yaojunhu2004@sohu.com ) \\ Northwest Agriculture and Forestry University https://orcid.org/0000-0001-6318-6576
}

\section{Research}

Keywords: Nicotinamide, Rumen fermentation, Mitochondrial respiratory chain, Lipid metabolism, Metabolomics

Posted Date: September 4th, 2020

DOI: https://doi.org/10.21203/rs.3.rs-68438/v1

License: (a) (i) This work is licensed under a Creative Commons Attribution 4.0 International License. Read Full License 


\section{Abstract}

Background: Improving energy efficiency is urgent during perinatal period because dairy ruminant is often in negative energy balance, resulting many metabolic disorders thus economic losses. It has been previously highlighted that nicotinamide (NAM) supplementation during perinatal period could benefit the energy balance, while the underlying metabolic alterations and the differences in NAM supplemented during different perinatal period have been poorly studied. This study aimed to elucidate the effects of NAM on energy efficiency, lipid metabolism, oxidative status, and liver metabolites profile of perinatal does during different perinatal period.

Results: Fifteen multiparous does with similar parity, weight, and previous milk yield were paired and allocated to 3 groups ( $\mathrm{n}=$ 5): control (C), postpartum supplementation (P, NAM supplemented after kidding), and entire-perinatal supplementation (EP, NAM supplemented from -21 to $28 \mathrm{~d}$ around kidding). Does were drenched with $5 \mathrm{~g} / \mathrm{d}$ of NAM and slaughtered on $\mathrm{d} 28$. The ruminal acetic acid tended to decrease, and the propionic acid and valeric acid were increased in $\mathrm{P}$ and EP. The does in $\mathrm{P}$ and EP had a decreased acetic acid to propionic acid ratio. Does in EP had higher liver mitochondrial respiratory chain complexes. The Complex $\nabla$ was elevated in both $\mathrm{P}$ and EP and NAM supplementation tended to increase ATP production. Liver metabolomics analysis and tissues biochemical analysis revealed that lipid was decomposed in abdominal adipose, and in liver, the decomposition of lipid was more than the synthesis, and the amino acid metabolism were enriched by NAM. Moreover, the oxidative status of blood and liver were improved by NAM supplementation, and supplementation of NAM during postpartum only does not appear enough to cope with the metabolites of oxidative phosphorylation.

Conclusions: Overall, these data suggested that NAM supplementation during perinatal period favored the rumen fermentation pattern to propionic acid-type, and improved liver energy efficiency with benefited lipid metabolism. The NAM supplemented from prepartum is needed for better oxidative status and energy metabolism of perinatal does.

\section{Background}

The dairy ruminant in perinatal period suffers significant metabolic challenges, with a 4-fold increase in energy requirement. However, the dry matter intake of the animal is limited. As the acetic acid and propionic acid were essential precursors for the synthesis of milk fat and glucose, respectively, the efficient rumen fermentation of the feed is important. Lipolysis occurs as a response to the negative energy balance (NEB) while leaving elevated nonesterified fatty acid (NEFA), which could induce lipid peroxidation and oxidative stress in hepatocytes[1]. Moreover, continuous hypermetabolic reaction results in augmented production of reactive oxygen species (ROS), leading to oxidative stress[2]. Many metabolic disorders occur in perinatal period such as lipidosis, mastitis, also infertility[3]. Thus, nutritional strategies to improve energy efficiency and alleviate oxidative status are urgently required for the health of perinatal dairy ruminant.

Nicotinamide (NAM) is the amide form of vitamin B3 and required for the synthesis of NAD and NADP, participating in many redox reactions. Our previous studies have shown that supplementing both NAM and biotin to transition dairy cows improved the energy balance, mainly through regulating glucose and lipid metabolism thus increasing the ATP production[4, 5]. Mitchell et al.[6] has proven that NAM could improve glucose metabolism by increasing glycogen deposition and flux through the pentose phosphate and glycolytic pathways. Moreover, the NAM was also proven to alleviate oxidative stress through decreasing NEFA, and $\beta$-hydroxybutyric acid, ROS, and improving glutathione metabolism in transition dairy cows $[4,5]$. The improved energy balance and health status then benefitted the offspring kids on small intestine morphology and function, and the hepatic glucose and lipid metabolism[7, 8]. However, there are still underlying regulatory mechanisms of NAM supplementation during the perinatal period. Since blood lipids are result of lipid absorption, lipid synthesis and lipid utilization rates, additional measures on dynamic lipid metabolism is needed to determine the mechanism of NAM action. In addition, whether the NAM supplemented during different perinatal period could affect the energy metabolism is still unknown.

Based on this, we hypothesized that NAM supplementation during different perinatal period could accelerate energy generation from nutrients oxidation and lipid metabolism accompanied with improved oxidative status. Liver is an important metabolic organ and plays important roles in energy metabolism, in which the energy production accounted for about $20 \%$ 
energy utilized by dairy ruminant[9]. Therefore, in this study the perinatal does were used as experimental object, and the objectives of this study were not only to evaluate the effects of NAM supplemented during different perinatal period on energy efficiency, lipid metabolism, oxidative status, but to profile the changes in liver metabolites associated with NAM using metabolomics approach.

\section{Materials And Methods}

This study was conducted in accordance with the guidelines of the Institutional Animal Care and Use Committee of Northwest A\&F University, Shaanxi, China, and was part of a larger study.

\section{Experimental design}

The experimental design was detailed described in Wei et al.[7] Briefly, fifteen Guanzhong dairy does with similar parity, weight, expected kidding date and previous milk yield were paired and randomly assigned within block to 3 groups. The 3 groups were: control (C, no supplementation), postpartum supplementation (P, NAM supplemented after kidding), and entire-perinatal supplementation (EP, NAM supplemented from -21 to $28 \mathrm{~d}$ around kidding). The $5 \mathrm{~g}$ of NAM was drenched to does daily at 0700. Does were housed in individual tie stalls and fed the same basal diets as total mixed ration (Table S-1). The experiment was conducted from 21 days before expected kidding date to 28 days postpartum. After kidding, does were milked twice daily.

\section{Rumen fluid, tissues and blood collection}

On the 28 days after kidding, the does were slaughtered. Ruminal fluid about $100 \mathrm{~mL}$ from individual doe was obtained. The $\mathrm{pH}$ was immediately measured and then rumen fluid was strained through 2-layer cheesecloth. The $4 \mathrm{~mL}$ of filtrate was mixed with $1 \mathrm{~mL}$ of $25 \%$ (wt/vol) metaphosphoric acid for the analysis of volatile fatty acid (VFA). The method we used was referred to former methodology in our lab[10].

Liver and abdominal adipose tissues from each individual were removed within 20 min postmortem, and snap frozen in liquid nitrogen. Blood was collected about $3 \mathrm{~h}$ after morning feeding from coccygeal vein once a week (i.e. $d-14( \pm 1),-7( \pm 1)$ relative to expected kidding day and d 1 (within $24 \mathrm{~h}$ ), 7, 14, 21, and 28 after kidding). Blood was centrifuged at $3500 \mathrm{~g}$ and $4^{\circ} \mathrm{C}$ for 15 min to obtain serum then stored at $-80^{\circ} \mathrm{C}$.

\section{Liver mitochondrial respiratory chain status}

Quantification of NAD and NADH were carried out using NAD/NADH assay kit from mlbio ${ }^{\circledR}$ (catalog no. ml341820-2 and ml341863-2, Shanghai, China), following the manufacturer's instructions. Livers were extracted at $4^{\circ} \mathrm{C}$ with extraction buffer provided by the kit. Complex I activity was measured by a modification of the Wallace method, and Complex II/III and complex IV activities were determined by measuring the reduction of cytochrome $\mathrm{C}$ or the oxidation of ferricytochrome $\mathrm{C}$ at $550-540 \mathrm{~nm}$, respectively, as previously described[11]. The ATP was measured using commercial kit (catalog no. HY-L0049) purchased from Beijing Sino-UK Institute of Biological Technology (Beijing, China).

\section{Lipid metabolism parameters}

The TG, NEFA, total cholesterol (TC), very low-density lipoprotein (VLDL), glycerin, and pyruvate kinase (PK) contents were measured using reagent kits purchased from Jiancheng Bioengineering Institute (Nanjing, China) following the instructions from the manufacturer. The activities of glutamyl transaminase (GPT) were analyzed using an auto analyzer at Northwest A\&F University (Shaanxi, China). The phosphoglycerol transferase 6 (AGPAT6), diacylglycerol transferase 2 (DGAT2), adiposetriglyceride-lipase (ATGL), hormone-sensitive lipase (HSL) activities were measured using ELISA method (goat catalog no. ml7089092, ml7098192, ml7091187, and ml7099870, respectively, mlbio ${ }^{\circledR}$, Shanghai, China). The values of the liver and abdominal adipose tissues were normalized by the protein concentration.

\section{Oxidative status measurements}


The blood activities of glutathione peroxidase (GSH-PX), superoxide dismutase (SOD) and catalase (CAT), the hydrogen peroxide $\left(\mathrm{H}_{2} \mathrm{O}_{2}\right)$ and malondialdehyde (MDA) concentrations, and total antioxidant capacity (T-AOC) were measured using commercial kits (Jiancheng Bioengineering Institute, Nanjing, China) following the manufacturer's instructions. Moreover, the SOD, T-AOC, CAT and MDA values of liver were normalized by protein concentration.

\section{Liver metabolomics analyses}

About $50 \pm 1 \mathrm{mg}$ of liver sample was taken into a $2 \mathrm{~mL}$ EP tubes, added with $450 \mu \mathrm{L}$ extraction liquid $\left(\mathrm{V}_{\text {Methanol }}: \mathrm{V}_{\mathrm{Chloroform}}=\right.$ 3:1) and $10 \mu \mathrm{L}$ of L-2-Chlorophenylalanine $\left(1 \mathrm{mg} / \mathrm{mL}\right.$, stock in $\mathrm{dH}_{2} \mathrm{O}$, serving as internal standard), vortexed, homogenized in ball mill at $45 \mathrm{~Hz}$ for $4 \mathrm{~min}$, and then ultrasound treated for $5 \mathrm{~min}$ (incubated in ice water). The solution was centrifuged at $12000 \mathrm{rpm}, 4^{\circ} \mathrm{C}$ for $15 \mathrm{~min}$, and a total of $350 \mu \mathrm{L}$ of the supernatant were transferred into fresh $1.5 \mathrm{~mL}$ EP tubes and dried in the vacuum concentrator. The dried residue was added with $50 \mu \mathrm{L}$ methoxy amination hydrochloride $(20 \mathrm{mg} / \mathrm{mL}$ in pyridine), mixed and incubated at $80^{\circ} \mathrm{C}$ for $30 \mathrm{~min}$. After that, $70 \mu \mathrm{L}$ of the BSTFA regent ( $1 \%$ TMCS, v/v) was added to the sample aliquots and incubated at $70^{\circ} \mathrm{C}$ for $1.5 \mathrm{~h}$. All samples were analyzed by gas chromatograph system coupled with a Pegasus HT time-of-flight mass spectrometer (GC-TOF-MS)[4].

\section{Statistical analysis}

Data were analyzed using the MIXED procedure of SAS. The REPEATED procedure was used for variables of blood, and the linear model was used for rumen and tissues parameters. The difference was considered significant at $P \leq 0.05$ and as a trend at $0.05<P \leq 0.10$. Moreover, the methods used to statistically analyze the liver metabolomics profile were followed the procedures we reported in Wei et al.[4] And in this study, the comparisons were made between every 2 groups, P vs. C, EP vs. C and $E P$ vs. $P$, and named $C_{P: C}, C_{E P: C}, C_{E P: P}$, respectively. The significant thresholds were variable importance in projection (VIP) $>1$, and $P<0.05$ (Student's t-test).

\section{Results}

\section{Rumen fermentation parameters}

In this study, compared to $C$, the ruminal propionic acid (expressed as percentage of total VFA) was increased in P and EP, and the propionic acid in $\mathrm{P}$ was higher than that in $\operatorname{EP}(P<0.001$, Table 1). The ruminal acetic acid tended to decrease $(P=0.069)$. The valeric acid was increased in $\mathrm{P}$ and EP $(P=0.018)$. Moreover, does in $\mathrm{P}$ and EP had a decreased acetic acid to propionic acid ratio $(P=0.001)$.

\section{Mitochondrial respiratory chain status}

The liver NADH concentration was elevated in EP as compared with $\mathrm{P}$ and $\mathrm{C}(P=0.001$, Table 2$)$. The NAD ${ }^{+}$or NAD ${ }^{+} / \mathrm{NADH}^{-}$ ratio were not affected in this study $(P>0.05)$. The mitochondrial complex I and $\nabla$ were increased in EP as compared with $\mathrm{P}$ and $\mathrm{C}(P=0.001)$, and complex $\otimes$ was higher in $\mathrm{P}$ and $\mathrm{EP}(P=0.036)$. Compared to $\mathrm{C}$, the complex $\otimes$ was increased in $\mathrm{EP}(P=$ 0.046). The production of ATP tended to increase $(P=0.069)$.

\section{Parameters related to lipid metabolism in abdominal adipose}

The TG content was lower in EP compared to $\mathrm{P}$ and $\mathrm{C}(P=0.001$, Table 3$)$, and the NEFA content was decreased in both $\mathrm{P}$ and $\mathrm{EP}(P=0.006)$. Compared to $\mathrm{C}$, the TC content was decreased in $\mathrm{P}$ and $\mathrm{EP}$, and the TC in EP was lower than that in $\mathrm{P}(P=$ 0.002). The enzyme activities of DGAT2 tended to decrease and the ATGL tended to increase by NAM supplementation ( $P=$ 0.072 and 0.063 , respectively). The activities of AGPAT6 and HSL were not affected $(P>0.10)$.

\section{Hepatic parameters and enzyme activities}


In liver, the TG content tended to decrease and the VLDL tended to increase by NAM supplementation $(P=0.079$ and 0.083 , respectively, Table 4). The NEFA content was not affected $(P>0.10)$. Compared to $C$, the glycerin was decreased in $P$ and EP $(P=0.010)$. The GPT was elevated in $\mathrm{P}$ as compared with EP and $\mathrm{C}(P=0.009)$. The enzyme activity of ATGL was increased in both $\mathrm{P}$ and EP $(P=0.037)$, and the PK and AGPAT6 activities tended to increase by NAM supplementation $(P=0.087$ and 0.091 , respectively). The activities of DGAT2 and HSL were not affected $(P>0.10)$.

\section{Blood parameters and oxidative status of blood and liver}

The blood TG and NEFA tended to decrease by NAM supplementation $(P=0.078$ and 0.099 , respectively, Table 5$)$, without the week $\times$ NAM effect. Serum TC was not affected by NAM, nor the week $\times$ NAM effect $(P>0.005)$.

Does in $\mathrm{P}$ had higher serum SOD compared to $\mathrm{C}(P=0.035$, Table 5), and a week $\times$ NAM effect was observed $(P=0.017)$. The CAT and CAT/SOD were increased in EP as compared with $\mathrm{P}$ and $\mathrm{C}(P<0.001)$, and tendencies existed for week $\times$ NAM effects $(P=0.062$ and 0.057 , respectively). Tendencies of increased GSH-PX and GSH-PX/SOD were present $(P=0.067$ and 0.061 , respectively) with no week $\times$ NAM effects. Serum $\mathrm{H}_{2} \mathrm{O}_{2}$ and MDA concentrations were not affected by NAM, and the week $\times$ NAM effect on $\mathrm{H}_{2} \mathrm{O}_{2}$ was found $(P=0.007)$. Time effects were noted for all blood parameters $(P<0.001)$. Liver SOD was increased in both $\mathrm{P}$ and EP $(P=0.034$, Figure 1$)$, and T-AOC was increased in EP compared to $\mathrm{C}(P=0.031)$.

\section{Liver metabolomics profile}

The results of regulated metabolites in $\mathrm{C}_{\mathrm{P}: \mathrm{C}}, \mathrm{C}_{\mathrm{EP}: \mathrm{C}}$, and $\mathrm{C}_{\mathrm{EP}: \mathrm{P}}$ were shown in Table 6. The diglycerol and cystine concentrations were decreased in $\mathrm{C}_{\mathrm{P}: \mathrm{C}}(P<0.05)$. The concentrations of sulfuric acid, malonic acid, 3-methylamino-1,2-propanediol, D-glyceric acid, ciliatine, hypoxanthine, palmitoleic acid and guanosine were found decreased in $\mathrm{C}_{\mathrm{EP}: \mathrm{C}}(P<0.05)$. And the uracil concentration was higher in $\mathrm{C}_{\mathrm{EP}: \mathrm{C}}(P<0.05)$. The liver 3-aminoisobutyric acid, cytidine-monophosphate and prostaglandin were decreased in both $\mathrm{C}_{\mathrm{P}: \mathrm{C}}$ and $\mathrm{C}_{\mathrm{EP}: \mathrm{C}}(P<0.05)$. In addition, we found that the malonamide was increased in $\mathrm{C}_{\mathrm{P}: \mathrm{C}}$, while lower

in $\mathrm{C}_{\mathrm{EP}: P}(P<0.05)$. The adenine tended to decrease in $\mathrm{C}_{\mathrm{P}: \mathrm{C}}$, while was higher in $\mathrm{C}_{\mathrm{EP}: \mathrm{P}}(P=0.073$ and 0.036 , respectively). The octadecanol tended to increase in $\mathrm{C}_{\mathrm{P}: \mathrm{C}}$ and was higher in $\mathrm{C}_{\mathrm{EP}: \mathrm{C}}(P=0.096$ and 0.030 , respectively).

The enriched pathways of altered metabolites were presented in metabolome view map $(P<0.05$, Figure 2$)$. There were no

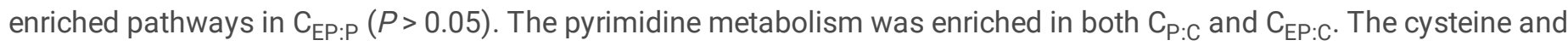
methionine metabolism was enriched in $\mathrm{C}_{\mathrm{P}: \mathrm{C}}$. And the $\mathrm{C}_{\mathrm{EP}: \mathrm{C}}$ had additional enriched pathway of purine metabolism, sulfur metabolism, pantothenate and CoA biosynthesis, glyoxylate and dicarboxylate metabolism, beta-alanine metabolism, glycerolipid metabolism, and glycine, serine and threonine metabolism.

\section{Discussion}

During perinatal period, about 70\% glucose was provided from hepatic gluconeogenesis[12]. Our previous studies have shown that NAM supplementation would relieve NEB[5] through improving glucose circulation[4]. The propionic acid is the main source of liver gluconeogenic substrate, and the ruminal propionic acid ratio was increased with NAM supplementation, suggesting the improved gluconeogenesis might be due to increased gluconeogenic substrate. This was in accordance with the result in Khan et al.[13] The increased propionic acid could be due to the altered NAD/NADH ratio in microbes, as NAM is a precursor of NAD. Another reason would be that niacin increased rumen protozoa numbers[14], which was shown to contribute to higher ruminal propionic acid level[15]. For ruminant, the acetic acid is the main precursor for de novo synthesis of fatty acid in mammary gland, and provides the majority of the carbon. The milk fat yield was increased by $20 \%$ when the acetate was ruminal infused to lactating dairy cows, and the de novo synthesized fatty acids and palmitic acid were also increased in milk[16]. In this study, however, the milk fat was not affected by the acetic acid that tended to be decreased[8]. The altered rumen fermentation pattern, tended to propionic acid-type, suggested that the NAM supplementation contributed to the effective fermentation of feed in the rumen and produced more energy metabolism substrates, favoring the NAM supplementation in perinatal period. 
The mitochondrion plays vital role in energy generation from nutrients oxidation,in which the electrons were transferred originating from metabolites to NAD[17]. As a precursor of NAD, NAM supplementation should increase NAD ${ }^{+}$level and subsequently increase its redox, i.e., $\mathrm{NAD}^{+} / \mathrm{NADH}$ ratio. However, we did not find increased liver $\mathrm{NAD}^{+}$or $\mathrm{NAD}^{+} / \mathrm{NADH}$ ratio, while elevated NADH concentrations in does supplemented NAM during entire-perinatal period. We presumed that NAM became $\mathrm{NAD}^{+}$when supplemented to does, rapidly being driven force to participate in the increased nutrients oxidation for the urgent energy requirement. Moreover, NAM supplementation provided a larger pool of pyridine nucleotides and the NADH pool may eventually get larger via the supply of $\mathrm{NAD}^{+}[18]$. The enriched pyridine metabolism found in both $\mathrm{C}_{\mathrm{P}: \mathrm{C}}$ and $\mathrm{C}_{\mathrm{EP}: \mathrm{C}}$ agreed with this discussion. Liver is an important metabolic organ and the mitochondrion has been referred as a power plant while passing electrons to produce ATP. The mitochondrial complex I catalyzes NADH oxidation to regenerate NAD ${ }^{+}$. It is a key enzyme in cellular energy metabolism and provides approximately $40 \%$ of the proton-motive force that is utilized during mitochondrial ATP production[19]. The complex $\nabla, \varangle$, and $\nabla$ are essential in the following reaction of mitochondrial respiratory

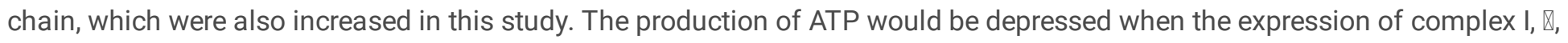
and $\otimes$ decreased[20]. The NAM supplementation caused an elevation in both mitochondrial respiration and ATP production, also supporting the results of improved NEB by NAM in our previous report[5].

However, the generation of ATP is usually accompanied by ROS production, which is the byproducts of oxidative phosphorylation[21]. A good balance between energy level and redox status is required to ensure optimal health during the perinatal period. Measuring enzymatic antioxidants (CAT, GSH-PX and SOD) together with MDA values could give more accurate information on oxidative stress level, rather than using such data separately. As a result of NAM supplementation, the serum antioxidase system (SOD, CAT, and GSH-PX activity) of antioxidant barrier in animals was enhanced, which was in accordance with the report of John et al.[22] The SOD reduces the superoxide radical into $\mathrm{H}_{2} \mathrm{O}_{2}$, which is the substrate then used by CAT to produce $\mathrm{H}_{2} \mathrm{O}$. When the imbalance between the CAT and SOD, the overexpression of SOD without a proportional compensatory increase in CAT, existed, it would cause a peroxide overload challenge and be deleterious upon the cell[23]. The does supplemented with NAM during entire-perinatal period had an increase in serum CAT/SOD ratio, indicating the ability of blood to cope with oxidative stress. The ROS production was elevated from a week prior kidding, so the NAM supplementation during postpartum was not effective to clear the $\mathrm{H}_{2} \mathrm{O}_{2}$. Moreover, in order to better understand the antioxidative protection, the ratio of GSH-PX to SOD was considered as its increase indicated an activation of the antioxidant enzyme to defense against ROS, while a decrease may be indicative of a lower scavenging efficiency then the oxidative damage may occur[24]. These alterations manifested as an enhancement in antioxidant capacity by NAM supplementation, further indicating the production and breakdown of ROS remained in homeostasis in does. And the NAM supplementation staring from prepartum was better for the does.

During the perinatal period, the body fat mobilization occurred in response to NEB. The AGPAT6 and DGAT2 are important enzymes in TG synthesis process, and ATGL and HSL are the key enzymes for TG decomposition[25, 26]. The enhanced ATGL was shown to reduce the fat content of the dorsal longest muscle in cattle steers[27]. In this study, with the supplementation of NAM, the synthesis of TG in abdominal adipose was decreased and the decomposition was increased, leaving TG, NEFA and TC in abdominal adipose were significantly reduced in this study. This result indicated that NAM supplementation during entire perinatal period helped the fat metabolization to provide large amount of NEFA into liver for metabolic energy supply. However, the accumulation of BHBA (incomplete oxidation of NEFA) and TG (re-esterification of NEFA) usually caused fatty liver, ketosis and oxidative stress[28,29]. It is worth noting that the decomposition of TG did not cause an increase, while a decrease in tendency, in the content of TG and NEFA in blood and liver. This would be due to the increased enzyme activity of ATGL and the VLDL concentration in the liver, thus the TG was decomposed to utilize or delivered. The differences in the effects of NAM on abdominal adipose and liver suggested the tissue specific of NAM during perinatal period. In study of Zachut et al.[30], the occurrence of insulin resistance in dairy cows during the perinatal period is tissue-specific, and there was no insulin resistance in liver tissue, while existed in fat tissue. We speculated that the tissue specific of NAM could be related to the tissue-specific of insulin resistance during perinatal period. A summary of the principal findings regarding the lipid metabolism of the abdominal adipose and liver was presented in Fig. 3. The interesting finding in this study was that the VLDL concentration tended to elevate in the liver. Our group previously found that the choline and methionine promoted liver fatty 
acid oxidation and VLDL synthesis, and reduced liver TG accumulation in dairy cows during the perinatal period[31]. As we know, the choline and methionine are important methyl donors, participating in the one-carbon unit cycle. When the amount of NAM supplementation was sufficient, it can participate in the methionine-homocysteine cycle and the methylation of substrate[32]. In addition, the enriched amino acid metabolism pathways were found by NAM supplementation. Therefore, the increasing trend of VLDL in the liver might be related to the NAM participation in the methionine cycle, which needs further validation.

\section{Conclusion}

The results presented in this study provided the first evidence that NAM supplementation during postpartum and entire perinatal period favored the rumen fermentation pattern to propionic acid-type, and altered the hepatic mitochondrial respiratory chain to generate ATP. Supplementation of NAM during postpartum only does not appear enough to cope with the metabolites of oxidative phosphorylation. The summary of the findings in this study was presented in Fig. 4. What is more, it is one-sided to judge the effect and mechanism of additive only through blood changes as the blood concentration is the comprehensive results of body metabolism. Our data suggested that NAM supplemented from prepartum is needed for better oxidative status and energy metabolism of perinatal does. More research is warranted to look at the effect and mechanism of NAM on urea metabolites.

\section{Abbreviations}

\section{AGPAT6}

phosphoglycerol transferase 6; ATGL:adipose-triglyceride-lipase; C, control group; P, postpartum group, NAM supplemented after kidding; EP, entire-perinatal group, NAM supplemented from - 21 to $28 \mathrm{~d}$ around kidding; $\mathrm{C}_{\mathrm{P}} \mathrm{C}_{\mathrm{C}}$, compare the $\mathrm{P}$ with the $\mathrm{C}$;

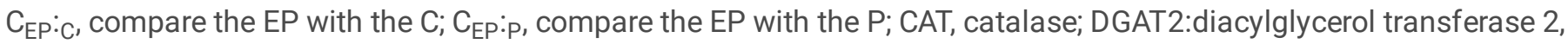
GPT:glutamyl transaminase; GSH-PX, glutathione peroxidase; $\mathrm{H}_{2} \mathrm{O}_{2}$, hydrogen peroxide; HSL:hormone-sensitive lipase; MDA, malondialdehyde; NEFA:nonesterified fatty acid; NAD, nicotinamide adenine dinucleotide; NADP, nicotinamide adenine dinucleotide phosphate; NADH, ubiquinone oxidoreductase; NAM, nicotinamide; NEB, negative energy balance; PK:pyruvate kinase; ROS, reactive oxygen species; SOD, superoxide dismutase; T-AOC, total antioxidant capacity; TC:total cholesterol; VLDL:very low-density lipoprotein; VIP, variable importance in projection.

\section{Declarations}

\section{Ethics approval and consent to participate}

The use of animals and all experimental protocols (protocol number 100403) were authorized by the Institutional Animal Care and Use Committee of Northwest A\&F University (Yangling, Shaanxi, China).

\section{Consent for publication}

Not applicable.

\section{Availability of data and materials}

All data were presented in the main manuscript and available to readers.

\section{Competing interests}

The authors declare that they have no conflict of interest.

\section{Funding}


Financial support was received from the Science \& Technological Project of Ningxia Autonomous Region, China (2018BBF33007), the Agricultural Special Fund of Shaanxi Province, China (NYKJ-2019-YL15), and the Research and Development Fund of Zhejiang A\&F University (2019FR051).

\section{Authors' contributions}

The authors' contributions were as follows: J. H. Y. and X. S. W. designed the experiment; X. S. W., Q. Y. Y., H. H. Z. and J. J. H. performed the experiment; X. S. W., Q. Y. Y., and Y. C. C. analyzed the data; X. S. W. wrote the manuscript. All the authors read and approved the final manuscript.

\section{Acknowledgments}

We are grateful to Lixin Zheng and the members of the Innovative Research Team of Animal Nutrition \& Healthy Feeding in Northwest A\&F University for providing valuable assistance in animal care and data analysis.

\section{References}

1. Shen, J.; Sun, B. F.; Yu, C.; Cao, Y. C.; Cai, C. J.; Yao, J. H. Choline and methionine regulate lipid metabolism via the AMPK signaling pathway in hepatocytes exposed to high concentrations of nonesterified fatty acids. J. Cell Biochem. 2019, 112.

2. Sordillo, L. M.; Mavangira, V. The nexus between nutrient metabolism, oxidative stress and inflammation in transition cows. Anim. Prod. Sci. 2014, 54(9), 1204-1214.

3. Roche, J. R.; Burke, C. R.; Crookenden, M. A.; Heiser, A.; Loor, J. L.; Meier, S.; Mitchell, M. D.; Phyn, C. V. C.; Turner, S. A. Fertility and the transition dairy cow. Reprod. Fertil. Dev. 2018, 30, 85-100.

4. Wei, X. S.; Yin, Q. Y.; Zhao, H. H.; Cao, Y. C.; Cai, C. J.; Yao, J. H. Metabolomics for the effect of biotin and nicotinamide on transition dairy cows. J. Agr. Food Chem. 2018a, 66, 5723-5732.

5. Wei, X. S.; Cai, C. J.; He, J. J.; Yu, C.; Mitloehner, F.; Liu, B. L.; Yao, J. H.; Cao, Y. C. Effects of biotin and nicotinamide supplementation on glucose and lipid metabolism and milk production of transition dairy cows. Anim. Feed Sci. Tech. 2018b, 237, 106-117.

6. Mitchell, S. J.; Bernier, M.; Aon, M. A.; Cortassa, S.; Kim, E. Y.; Fang, E. F.; Palacios, H. H.; Ali, A.; Navas-Enamorado, I.; Di Francesco, A.; Kaiser, T. A.; Waltz, T. B.; Zhang, N.; Ellis, J. L.; Elliott, P. J.; Frederick, D. W.; Bohr, V. A.; Schmidt, M. S.; Brenner, C.; Sinclair, D. A.; Sauve, A. A.; Baur, J. A.; de Cabo, R. Nicotinamide improves aspects of healthspan, but not lifespan, in mice. Cell Metab. 2018, 27(3), 667-676.e4.

7. Wei, X. S.; Zhao, H. H.; He, J. J.; Yin, Q. Y.; Cao, Y. C.; Cai, C. J.; Yao, J. H. Maternal nicotinamide supplementation during the perinatal period modifies the small intestine morphology and antioxidative status of offspring kids. Anim. Feed Sci. Tech. $2019,252,41-50$.

8. Wei, X. S.; Yin, Q. Y.; Zhao, H. H.; Jiang, H.; He, J. J.; Cai, C. J.; Cao, Y. C.; Yao, J. H. Maternal nicotinamide supplementation during late gestation and early lactation alters hepatic glucose and lipid metabolism kids. Anim. Feed Sci. Tech. 2020, $267,114528$.

9. Ingvartsen, K. L.; Moyes, K. Nutrition, immune function and health of dairy cattle. Animal. 2013, 7(I), 112-122.

10. Li, F.; Cao, Y.; Liu, N.; Yang, X.; Yao, J.; Yan, D. Subacute ruminal acidosis challenge changed in situ degradability of feedstuffs in dairy goats. J. Dairy Sci. 2014, 97(8), 5101-5109.

11. Trounce, I. A.; Kim, Y. L.; Jun, A. S.; Wallace, D. C. Assessment of mitochondrial oxidative phosphorylation in patient muscle biopsies.; lymphoblasts, and transmitochondrial cell lines. Method Enzymol. 1996, 264, 484-509.

12. Aschenbach.; J. R.; Kristensen.; N. B.; Donkin.; S. S.; Hammon.; H. M.; Penner.; G. B. Gluconeogenesis in dairy cows: the secret of making sweet milk from sour dough. IUBMB Life. 2010, 62.; 869-877. 
13. Khan, N.; Kewalramani, N.; Chaurasia, M.; Singh, S.; Haq, Z. Effect of niacin supplementation on in-vitro rumen fermentation pattern in crossbred cattle. Indian J. Anim. Res. 2015, 5(3), 479-483.

14. Aschemann.; M.; Lebzien.; P.; Hüther.; L.; Südekum.; K. H.; Dänicke.; S. Effect of niacin supplementation on rumen fermentation characteristics and nutrient flow at the duodenum in lactating dairy cows fed a diet with a negative rumen nitrogen balance. Arch. Anim. Nutr. 2012, 66(4), 303-318.

15. Erickson, P. S.; Trusk, T. M.; Murphy, M. R. Effect of niacin source on epinephrine stimulation of plasma NEFA and glucose concentration on diet digestibility and on rumen protozoal numbers in lactating dairy cows. J. Nutr. 1990, 120, 1648-1653.

16. Urrutia, N. L.; Harvatine, K. Effect of conjugated linoleic acid and acetate on milk fat synthesis and adipose lipogenesis in lactating dairy cows. J. Dairy Sci. 2017, 100(7), 1-13.

17. Dröse, S.; Stepanova, A.; Galkin, A. Ischemic A/D transition of mitochondrial complex I and its role in ROS generation. Biochim. Biophys. Acta. 2016, 1857, 946-957.

18. Klaidman, L. K.; Mukherjee, S. K.; Jr Adams, J. D. Oxidative changes in brain pyridine nucleotides and neuroprotection using nicotinamide. Biochim. Biophys. Acta. 2001, 1525, 136-148.

19. Hirst, J. Mitochondrial complex I. Annu. Rev. Biochem. 2013, 82, 551-575.

20. Sun, Q.; Zhong, W.; Zhang, W.; Zhou, Z. Defect of mitochondrial respiratory chain is a mechanism of ROS overproduction in a rat model of alcoholic liver disease: role of zinc deficiency. Am. J. Physiol-Gastr. L. 2015, 310, G205.

21. Schiavi, A.; Ventura, N. The interplay between mitochondria and autophagy and its role in the aging process. Exp. Gerontol. 2014, 56, 147-153.

22. John, C. M.; Ramasamy, R.; Al, N. G.; Al-Nuaimi, A. H.; Adam, A. Nicotinamide supplementation protects gestational diabetic rats by reducing oxidative stress and enhancing immune responses. Curr. Med. Chem. 2012, 19, 5181-5186.

23. Pinho, R. A.; Andrades, M. E.; Oliveira, M. R.; Pirola, A. C.; Zago, M. S.; Silveira, P. C.; Dal-Pizzol, F.; Moreira, J. C. Imbalance in SOD/CAT activities in rat skeletal muscles submitted to treadmill training exercise. Cell Biol. Int. 2006, 30, 848-853.

24. Amicarelli.; F.; Ragnelli.; A. M.; Aimola.; P.; Bonfigli.; A.; Colafarina.; S.; Di llio.; C.; Miranda.; M. Age-dependent ultrastructural alterations and biochemical response of rat skeletal muscle after hypoxic or hyperoxic treatments. BBA-Mol. Basis Dis. 1999, 1453, 105-114.

25. Huang, H.; Zhang, Y.; Cao, M.; Xue, L.; Shen, W. Effects of fasting on the activities and mRNA expression levels of lipoprotein lipase (LPL).; hormone-sensitive lipase (HSL) and fatty acid synthetase (FAS) in spotted seabass Lateolabrax maculatus. Fish Physiol. Biochem. 2018, 44(1), 387-400.

26. Karbowska, J.; Kochan, Z. Fat-reducing effects of dehydroepiandrosterone involve upregulation of ATGL and HSL expression, and stimulation of lipolysis in adipose tissue. Steroids. 2012, 77(13), 1359-1365.

27. Jeong, J.; Kwon, E. G.; Im, S. K.; Seo, K. S.; Baik, M. Expression of fat deposition and fat removal genes is associated with intramuscular fat content in longissimus dorsi muscle of Korean cattle steers. J. Anim. Sci. 2012, 90(6), 2044-2053.

28. Abdelli.; A.; Raboisson.; D.; Kaidi.; R.; Ibrahim.; B.; Kalem.; A.; Iguer-Ouada.; M. Elevated non-esterified fatty acid and $\beta$ hydroxybutyrate in transition dairy cows and their association with reproductive performance and disorders: A metaanalysis. Theriogenology. 2017, 93, 99-104.

29. Gerspach, C.; Imhasly, S.; Gubler, M.; Naegeli, H.; Ruetten, M.; Laczko, E. Altered plasma lipidome profile of dairy cows with fatty liver disease. Res. Vet. Sci. 2017, 110, 47-59.

30. Zachut, M.; Honig, H.; Striem, S.; Bourahalfon, S.; Moallem, U. Periparturient dairy cows do not exhibit hepatic insulin resistance, yet adipose-specific insulin resistance occurs in cows prone to high weight loss. J. Dairy Sci. 2013, 96(9):56565669.

31. Sun, F.; Cao, Y.; Cai, C.; Li, S.; Yu, C.; Yao, J. Regulation of nutritional metabolism in transition dairy cows: energy homeostasis and health in response to post-ruminal choline and methionine. PloS One. 2016, 11(8), e0160659.

32. Li, D.; Tian, Y. J.; Guo, J.; Sun, W. P.; Lun, Y. Z.; Guo, M.; Luo, N.; Cao, Y.; Cao, J. M.; Gong, X. J.; Zhou, S. S. Nicotinamide supplementation induces detrimental metabolic and epigenetic changes in developing rats. Brit. J. Nutr. 2013, 110(12), 2156-2164. 
Tables

Table 1. Effect of nicotinamide supplementation during different period on rumen fermentation parameters of perinatal does.

\begin{tabular}{|lccccc|}
\hline Items & \multicolumn{2}{l}{ Treatments } & SEM & P-value \\
\cline { 2 - 4 } & $\mathrm{C}^{1}$ & $\mathrm{P}^{1}$ & $\mathrm{EP}$ & & \\
$\mathrm{yH}$ & 7.73 & 6.50 & 7.01 & 0.694 & 0.307 \\
\hline Total VFAZmmol/L】 & 62.43 & 56.72 & 62.79 & 4.072 & 0.816 \\
\hline Individual VFA, \% of total VFA & & & & \\
\hline Acetic acid (A) & 67.91 & 65.72 & 65.96 & 0.454 & 0.069 \\
\hline Propionic acid (P) & $15.68^{\mathrm{C}}$ & $17.40^{\mathrm{a}}$ & $16.79^{\mathrm{b}}$ & 0.230 & $<0.001$ \\
\hline Isobutyric acid & 1.72 & 2.01 & 2.03 & 0.105 & 0.476 \\
\hline Butyric acid & 10.59 & 11.06 & 10.48 & 0.328 & 0.787 \\
\hline Isovaleric acid & 2.32 & 2.76 & 2.76 & 0.135 & 0.363 \\
\hline Valeric acid & $1.11^{\mathrm{b}}$ & $1.25^{\mathrm{a}}$ & $1.29^{\mathrm{a}}$ & 0.030 & 0.018 \\
\hline A:P ratio & $4.36^{\mathrm{a}}$ & $3.78^{\mathrm{b}}$ & $3.93^{\mathrm{b}}$ & 0.080 & 0.001 \\
\hline
\end{tabular}

${ }^{1} \mathrm{C}$ : control; P: postpartum supplementation; EP: entire-perinatal supplementation.

a, bValues in the same row with different small letter superscripts mean significant difference $(P \leq 0.05)$, while the same or no letter superscripts mean no significant difference $(P>0.05) ; \mathrm{n}=5$.

Table 2. Effect of nicotinamide supplementation during different period on liver mitochondrial respiratory chain status of perinatal does.

\begin{tabular}{|c|c|c|c|c|c|}
\hline \multirow[t]{2}{*}{ Items } & \multicolumn{3}{|c|}{ Treatments } & \multirow[t]{2}{*}{ SEM } & \multirow[t]{2}{*}{$P$-value } \\
\hline & $\mathrm{C}^{1}$ & $\mathrm{P}^{1}$ & $\mathrm{EP}^{1}$ & & \\
\hline $\mathrm{NAD}^{+}(\mathrm{ng} / \mathrm{mL})$ & 3.29 & 3.50 & 3.72 & 0.156 & 0.578 \\
\hline NADH (ng/mL) & $4.77^{b}$ & $5.14^{\mathrm{b}}$ & $6.16^{a}$ & 0.187 & 0.001 \\
\hline $\mathrm{NAD}^{+} / \mathrm{NADH}$ & 0.69 & 0.64 & 0.60 & 0.023 & 0.289 \\
\hline Complex I (ng/mL) & $7.05^{b}$ & $7.06^{\mathrm{b}}$ & $9.02^{a}$ & 0.291 & 0.001 \\
\hline Complex $\otimes(\mathrm{ng} / \mathrm{mL})$ & $5.70^{\mathrm{b}}$ & $6.89^{a}$ & $6.35^{\mathrm{a}}$ & 0.198 & 0.036 \\
\hline Complex $\otimes(\mathrm{ng} / \mathrm{mL})$ & $5.46^{\mathrm{b}}$ & $5.55^{\mathrm{b}}$ & $6.75^{\mathrm{a}}$ & 0.188 & 0.001 \\
\hline Complex $\otimes(\mathrm{ng} / \mathrm{mL})$ & $3.15^{b}$ & $3.74^{\mathrm{ab}}$ & $4.57^{a}$ & 0.245 & 0.046 \\
\hline ATP $(\mathrm{nmol} / \mathrm{mL})$ & 1.69 & 1.83 & 2.11 & 0.762 & 0.069 \\
\hline
\end{tabular}

${ }^{1} \mathrm{C}$ : control; P: postpartum supplementation; EP: entire-perinatal supplementation. 
a, bValues in the same row with different small letter superscripts mean significant difference $(P \leq 0.05)$, while the same or no letter superscripts mean no significant difference $(P>0.05) ; \mathrm{n}=5$.

Table 3. Effect of nicotinamide supplementation during different period on abdominal adipose tissue parameters of perinatal does.

\begin{tabular}{|llllll|}
\hline \multirow{2}{*}{ Items $^{2}$} & \multicolumn{2}{l}{ Treatments } & & SEM & $P$-value \\
\cline { 2 - 5 } & $\mathrm{C}^{1}$ & $\mathrm{P}^{1}$ & $\mathrm{EP}^{1}$ & & \\
\hline TG (mmol/gprot) & $10.28^{\mathrm{a}}$ & $9.57^{\mathrm{a}}$ & $6.57^{\mathrm{b}}$ & 0.59 & 0.001 \\
\hline NEFA (mmol/gprot) & $1.83^{\mathrm{a}}$ & $0.57^{\mathrm{b}}$ & $0.40^{\mathrm{b}}$ & 0.23 & 0.006 \\
\hline TC (mmol/gprot) & $1.69^{\mathrm{a}}$ & $1.14^{\mathrm{b}}$ & $0.64^{\mathrm{c}}$ & 0.15 & 0.002 \\
\hline AGPAT6 (U.L) & 47.7 & 47.2 & 44.7 & 1.21 & 0.666 \\
\hline DGAT2 (U.L) & 89.9 & 80.2 & 67.7 & 1.42 & 0.072 \\
\hline ATGL (IU.L) & 182.3 & 188.4 & 203.4 & 3.81 & 0.063 \\
\hline HSL (U.L) & 631.3 & 647.3 & 680.5 & 18.3 & 0.580 \\
\hline
\end{tabular}

${ }^{1} \mathrm{C}$ : control; P: postpartum supplementation; EP: entire-perinatal supplementation.

${ }^{2} \mathrm{TG}=$ triglyceride; NEFA= nonesterified fatty acid; $\mathrm{TC}=$ total cholesterol; AGPAT6 = 1-acylglycerol-3-phosphate acyltransferases 6; DGAT2 = diacylglycerol acyltransferase 2; ATGL = adipose triglyceride lipase; $\mathrm{HSL}=$ hormone-sensitive lipase; ATP = adenosine triphosphate.

a, bValues in the same row with different small letter superscripts mean significant difference $(P \leq 0.05)$, while the same or no letter superscripts mean no significant difference $(P>0.05) ; \mathrm{n}=5$.

Table 4. Effect of nicotinamide supplementation during different period on liver parameters of perinatal does.

\begin{tabular}{|c|c|c|c|c|c|}
\hline \multirow[t]{2}{*}{ Items $^{2}$} & \multicolumn{3}{|c|}{ Treatments } & \multirow[t]{2}{*}{ SEM } & \multirow[t]{2}{*}{$P$-value } \\
\hline & $C^{1}$ & $P^{1}$ & $\mathrm{EP}^{1}$ & & \\
\hline TG (mmol/gprot) & 0.330 & 0.333 & 0.319 & 0.003 & 0.079 \\
\hline NEFA (mmol/gprot) & 0.033 & 0.035 & 0.037 & 0.002 & 0.694 \\
\hline VLDL (mmol/gprot) & 0.058 & 0.126 & 0.087 & 0.012 & 0.083 \\
\hline glycerin $\left(\mathrm{U} \cdot \mathrm{g}^{-1}\right)$ & $0.043^{\mathrm{a}}$ & $0.037^{b}$ & $0.038^{b}$ & 0.001 & 0.010 \\
\hline GPT (U/g) & $3.62^{b}$ & $5.21^{a}$ & $2.22^{\mathrm{b}}$ & 0.42 & 0.009 \\
\hline PK (U/gprot) & 8.36 & 15.74 & 10.96 & 1.42 & 0.087 \\
\hline AGPAT6 $\left(U \cdot L^{-1}\right)$ & 70.3 & 76.4 & 73.3 & 1.19 & 0.091 \\
\hline DGAT2 $\left(U \cdot L^{-1}\right)$ & 121.8 & 114.7 & 113.5 & 3.36 & 0.589 \\
\hline ATGL $\left(I U \cdot L^{-1}\right)$ & $231.4^{b}$ & $265.2^{\mathrm{a}}$ & $252.1^{\mathrm{a}}$ & 6.08 & 0.037 \\
\hline $\mathrm{HSL}\left(\mathrm{U} \cdot \mathrm{L}^{-1}\right)$ & 181.9 & 190.5 & 199.9 & 6.64 & 0.579 \\
\hline
\end{tabular}


${ }^{1} \mathrm{C}$ : control; P: postpartum supplementation; EP: entire-perinatal supplementation.

${ }^{2} \mathrm{TG}$ = triglyceride; NEFA= nonesterified fatty acid; VLDL = very low-density lipoprotein; GPT = glutamic-pyruvic transaminase; PK = pyruvate kinase; AGPAT6 = 1-acylglycerol-3-phosphate acyltransferases 6; DGAT2 = diacylglycerol acyltransferase 2; ATGL = adipose triglyceride lipase; HSL = hormone-sensitive lipase;

a, bValues in the same row with different small letter superscripts mean significant difference $(P \leq 0.05)$, while the same or no letter superscripts mean no significant difference $(P>0.05) ; \mathrm{n}=5$.

Table 5. Effect of nicotinamide supplementation during different period on blood fatty acid and oxidative status of perinatal does.

\begin{tabular}{|c|c|c|c|c|c|c|c|}
\hline \multirow[t]{2}{*}{ Items ${ }^{2}$} & \multicolumn{3}{|c|}{ Treatments } & \multirow[t]{2}{*}{ SEM } & \multicolumn{3}{|l|}{$P$-value } \\
\hline & $C^{1}$ & $P^{1}$ & $\mathrm{EP}^{1}$ & & Wk. & NAM & Wk. $\times$ NAM \\
\hline TG (mmol/L) & 0.22 & 0.16 & 0.15 & 0.01 & $<0.001$ & 0.078 & 0.291 \\
\hline NEFA (mmol/L) & 0.17 & 0.11 & 0.10 & 0.01 & $<0.001$ & 0.099 & 0.182 \\
\hline TC (mmol/L) & 2.12 & 1.96 & 1.86 & 0.08 & 0.016 & 0.405 & 0.341 \\
\hline $\mathrm{H}_{2} \mathrm{O}_{2}(\mathrm{U} / \mathrm{mL})$ & 52.69 & 54.04 & 51.61 & 1.505 & $<0.001$ & 0.537 & 0.007 \\
\hline $\mathrm{MDA}(\mathrm{mmol} / \mathrm{mL})$ & 1.43 & 1.37 & 1.39 & 0.067 & $<0.001$ & 0.829 & 0.677 \\
\hline $\mathrm{SOD}(\mathrm{U} / \mathrm{mL})$ & $57.31^{b}$ & $62.59^{a}$ & $59.31^{\mathrm{ab}}$ & 1.259 & $<0.001$ & 0.035 & 0.017 \\
\hline CAT (U/mL) & $2.454^{b}$ & $2.677^{b}$ & $3.636^{a}$ & 0.152 & $<0.001$ & $<0.001$ & 0.062 \\
\hline GSH-PX (U/mL) & 625.7 & 779.0 & 748.7 & 61.11 & $<0.001$ & 0.067 & 0.257 \\
\hline CAT/SOD & $0.045^{b}$ & $0.045^{b}$ & $0.062^{a}$ & 0.002 & $<0.001$ & $<0.001$ & 0.057 \\
\hline GSH-PX/SOD & 10.62 & 11.11 & 12.45 & 0.502 & $<0.001$ & 0.061 & 0.434 \\
\hline
\end{tabular}

${ }^{1} \mathrm{C}$ : control; P: postpartum supplementation; EP: entire-perinatal supplementation.

${ }^{2} \mathrm{TG}=$ triglyceride; $\mathrm{NEFA}=$ nonesterified fatty acid; $\mathrm{TC}$ = total cholesterol; $\mathrm{H}_{2} \mathrm{O}_{2}$ : hydrogen peroxide; MDA: malonaldehyde; SOD: superoxide dismutase; CAT: catalase; GSH-PX: glutathione peroxidase.

a, bValues in the same row with different small letter superscripts mean significant difference $(P \leq 0.05)$, while the same or no letter superscripts mean no significant difference $(P>0.05) ; \mathrm{n}=5$.

Table 6. Identification of different hepatic metabolites of does supplemented with nicotinamide. 


\begin{tabular}{|c|c|c|c|c|c|c|c|c|c|c|}
\hline \multirow[t]{2}{*}{ Metabolites } & \multirow[t]{2}{*}{$\mathrm{RT}^{1}$} & \multicolumn{3}{|l|}{$C_{P: C^{2}}$} & \multicolumn{3}{|l|}{$C_{E P: C^{2}}$} & \multicolumn{3}{|l|}{$C_{E P: P^{2}}^{2}$} \\
\hline & & VIP 3 & $\begin{array}{l}P- \\
\text { value }\end{array}$ & $\mathrm{FC}^{3}$ & VIP 3 & $\begin{array}{l}P \text { - } \\
\text { value }\end{array}$ & $\mathrm{FC}^{3}$ & VIP3 & $\begin{array}{l}P \text { - } \\
\text { value }\end{array}$ & $\mathrm{FC}^{3}$ \\
\hline sulfuric acid & 8.962 & 0.551 & 0.438 & 1.963 & 2.018 & 0.048 & 0.735 & 1.026 & 0.338 & 0.374 \\
\hline malonic acid & 9.394 & 0.817 & 0.374 & 1.701 & 2.525 & $<0.001$ & 0.763 & 1.298 & 0.258 & 0.448 \\
\hline $\begin{array}{l}\text { 3-methylamino- } \\
\text { 1,2-propanediol }\end{array}$ & 9.574 & 0.688 & 0.726 & 1.234 & 1.652 & 0.025 & 0.304 & 0.574 & 0.187 & 0.246 \\
\hline $\begin{array}{l}3- \\
\text { aminoisobutyric } \\
\text { acid }\end{array}$ & 9.582 & 1.861 & 0.041 & 0.166 & 2.088 & 0.027 & 0.244 & 0.911 & 0.425 & 1.472 \\
\hline D-glyceric acid & 11.229 & 0.900 & 0.332 & 1.619 & 1.998 & 0.035 & 0.775 & 1.315 & 0.214 & 0.479 \\
\hline uracil & 11.356 & 0.743 & 0.278 & 4.602 & 2.379 & 0.006 & 4.532 & 0.891 & 0.981 & 0.985 \\
\hline malonamide & 14.085 & 1.061 & 0.023 & 2.647 & 0.104 & 0.778 & 0.855 & 1.247 & 0.012 & 0.323 \\
\hline ciliatine & 16.283 & 0.854 & 0.568 & 0.792 & 2.320 & 0.020 & 0.536 & 0.698 & 0.489 & 0.677 \\
\hline diglycerol & 16.292 & 1.737 & 0.014 & 0.169 & 0.672 & 0.936 & 0.963 & 1.679 & 0.118 & 5.694 \\
\hline hypoxanthine & 17.054 & 1.294 & 0.101 & 0.424 & 2.218 & 0.008 & 0.149 & 0.855 & 0.378 & 0.351 \\
\hline adenine & 17.683 & 1.619 & 0.073 & $<0.001$ & 0.956 & 0.458 & 1.430 & 2.274 & 0.036 & 36228.2 \\
\hline palmitoleic acid & 19.242 & 0.422 & 0.471 & 1.371 & 1.282 & 0.039 & 0.496 & 1.092 & 0.118 & 0.362 \\
\hline octadecanol & 20.462 & 1.023 & 0.096 & 2.523 & 1.093 & 0.030 & 2.453 & 0.084 & 0.934 & 0.972 \\
\hline cystine & 21.658 & 1.694 & 0.009 & 0.351 & 1.185 & 0.345 & 0.667 & 0.939 & 0.330 & 1.901 \\
\hline $\begin{array}{l}\text { cytidine- } \\
\text { monophosphate }\end{array}$ & 23.011 & 1.744 & 0.005 & 0.165 & 2.109 & 0.010 & 0.194 & 0.315 & 0.910 & 1.182 \\
\hline prostaglandin & 24.829 & 2.179 & 0.030 & $<0.001$ & 2.673 & 0.030 & $<0.001$ & 1.050 & 0.314 & 0.485 \\
\hline guanosine & 25.368 & 0.437 & 0.523 & 1.361 & 1.101 & 0.037 & 0.506 & 0.735 & 0.156 & 0.372 \\
\hline
\end{tabular}

${ }^{1}$ RT: retention time, minute.

${ }^{2} \mathrm{C}_{\mathrm{P}: \mathrm{C}}$ : hepatic metabolite in postpartum versus that in control, $\mathrm{C}_{\mathrm{EP}: \mathrm{C}}$ : hepatic metabolite in entire-perinatal versus that in control, and $\mathrm{C}_{\mathrm{EP}: \mathrm{P}}$ : hepatic metabolite in entire-perinatal versus that in postpartum.

${ }^{3}$ VIP: variable importance in projection. FC: fold change, calculated as the mean value of peak area obtained from treatment group/mean value of peak area obtained from control group. If the FC value is less than 1 , it means that there is less metabolite in treatment group than in control group.

\section{Figures}



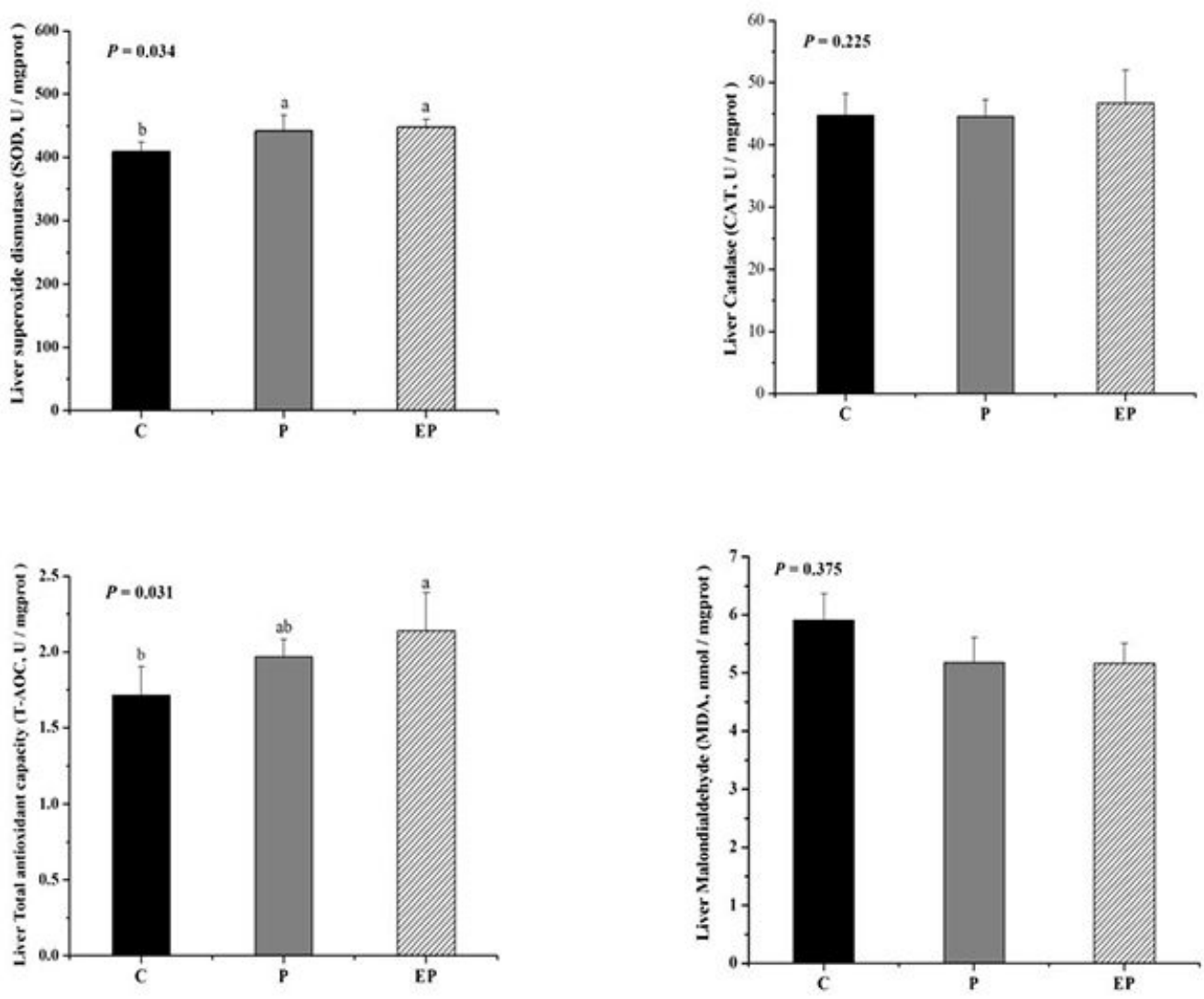

\section{Figure 1}

Effect of nicotinamide supplementation on liver oxidative status of perinatal does. C: control; P: postpartum supplementation; EP: entire-perinatal supplementation. Data were presented as mean \pm SEM. a, bValues with different small letter superscripts mean significant difference $(P \leq 0.05)$, while the same or no letter superscripts mean no significant difference $(P>0.05)$. 

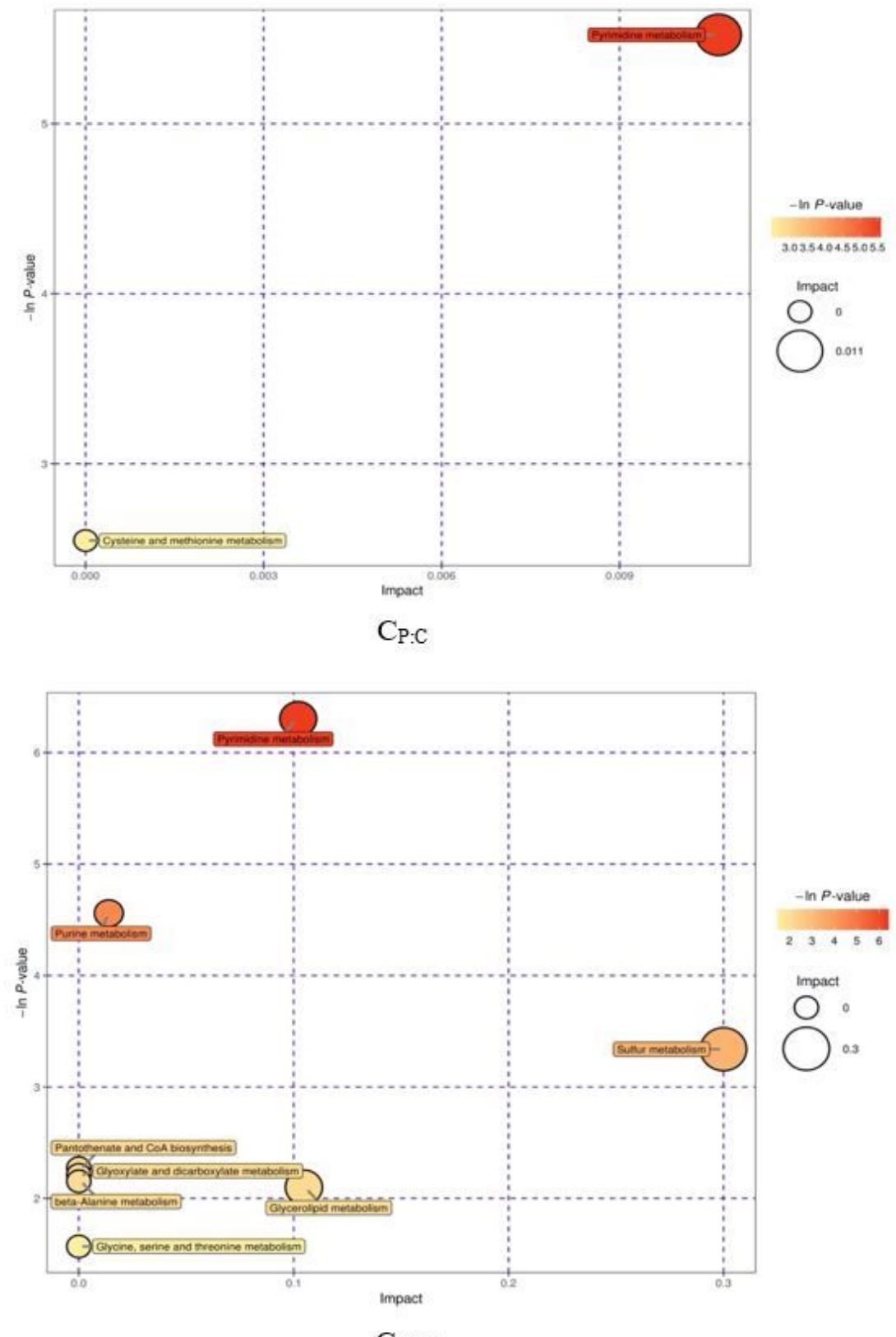

CEP:C

\section{Figure 2}

Metabolome view map of common metabolites identified in liver. CP:C and CEP:C were used to represent the comparison of $P$ and EP with C, respectively. C: control; P: postpartum supplementation; EP: entire-perinatal supplementation. The $x$ axis represents the pathway impact, and y axis represents the pathway enrichment. 


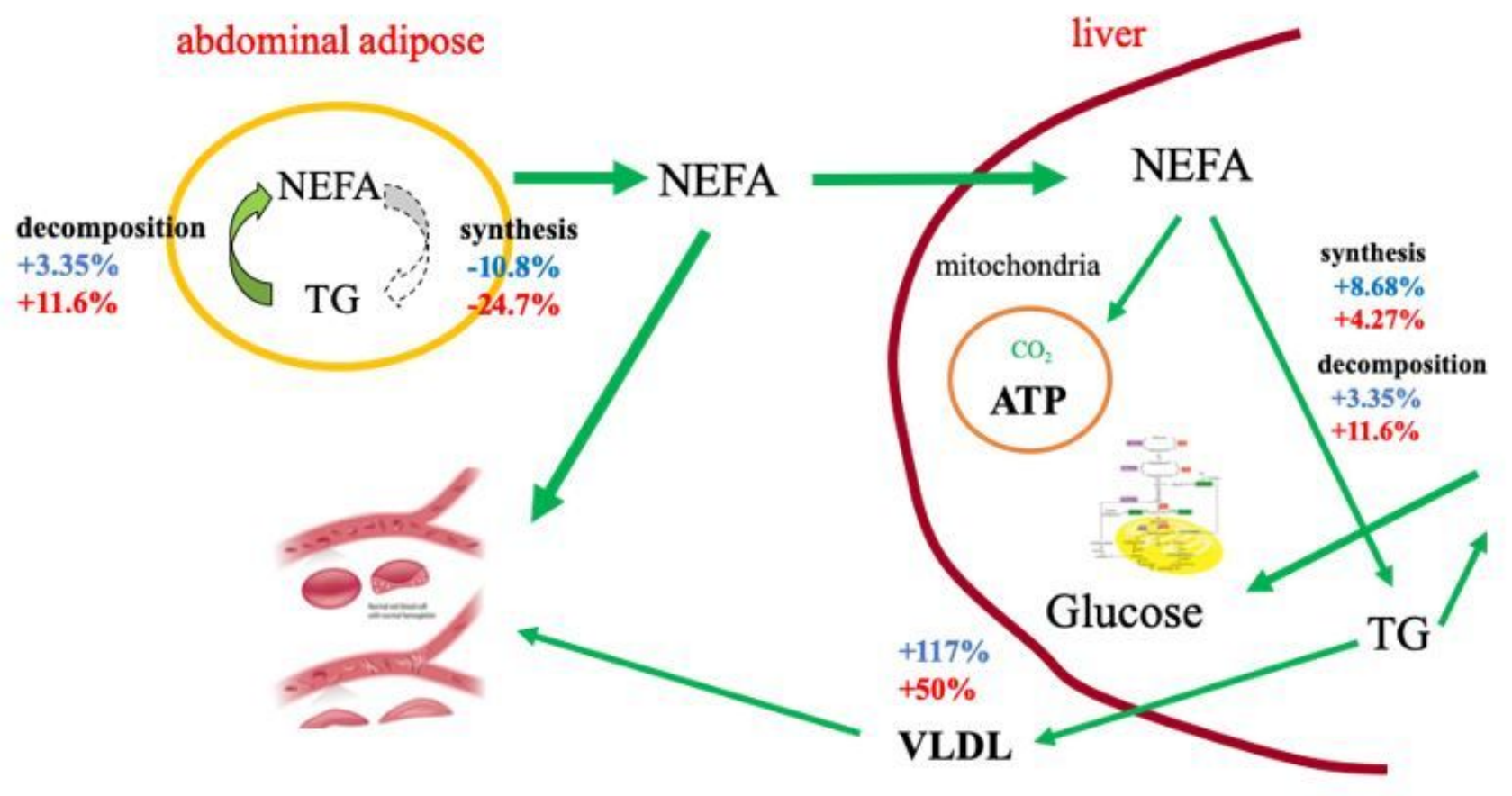

Figure 3

Interrelationships among metabolites of lipid metabolism in the abdominal adipose and liver tissues in P and EP. C: control; P: postpartum supplementation; EP: entire-perinatal supplementation. Note: blue numbers denote the changes in P group, and red numbers denote the changes in EP group.
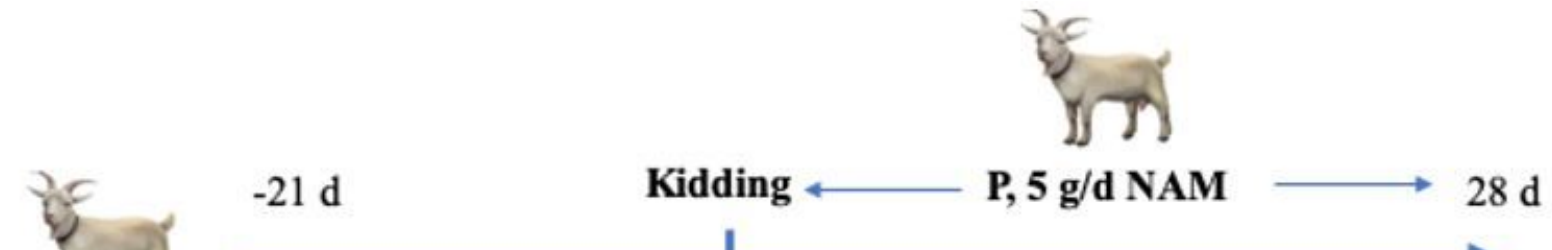

EP, 5 g/d NAM
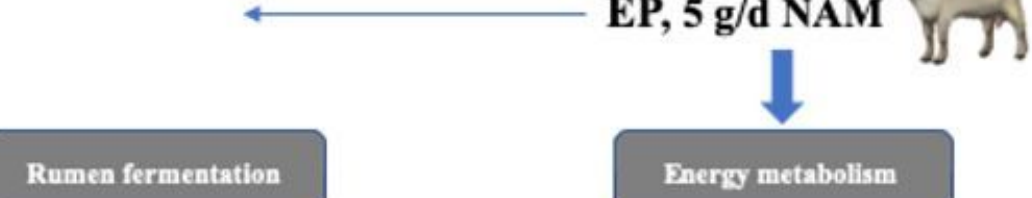

Fnergy metabolism

Metabolomies analysis of liver

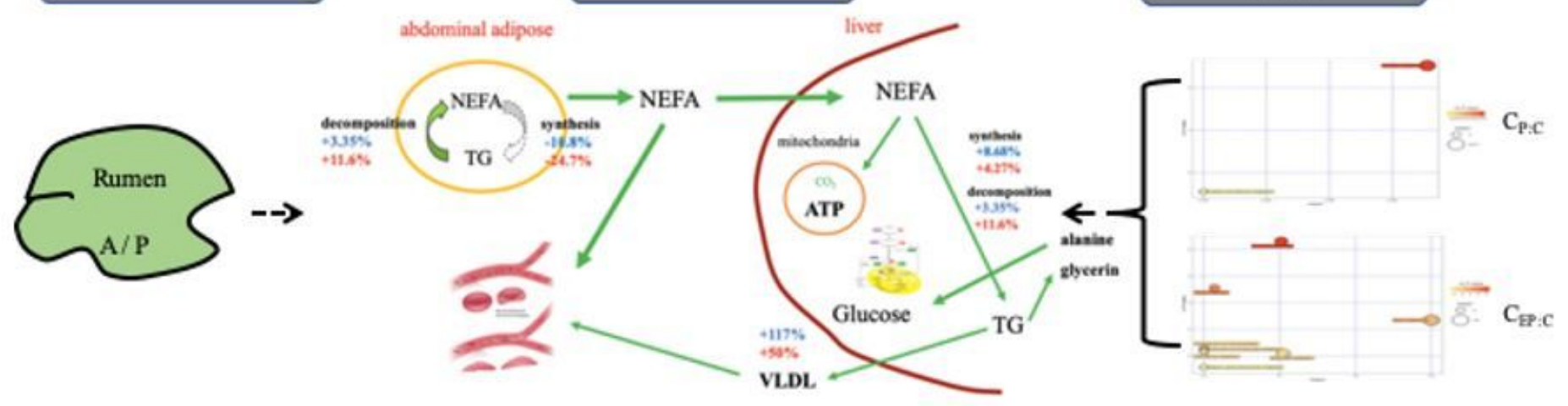

Figure 4 
The summary of the findings in this study.

\section{Supplementary Files}

This is a list of supplementary files associated with this preprint. Click to download.

- GraphicalAbstract.jpg

- GraphicalAbstract.jpg

- Supplementaryfileforonlinepublicationonly.docx

- Supplementaryfileforonlinepublicationonly.docx 